\title{
A record based analysis of treatment outcome in Tuberculosis patients registered under Tuberculosis unit, Umbraj, District Satara of Western Maharashtra
}

\author{
Ravindra Y Mandolikar ${ }^{1}$, R.H. Patil ${ }^{2 *}$, N. S. Madhekar ${ }^{3}$, D.K. Mahabalaraju ${ }^{4}$ \\ ${ }^{1,2}$ Assistant Professor, ${ }^{3,4}$ Professor, ${ }^{1-4}$ Dept. of Community Medicine, ${ }^{1,4}$ Shridevi Institute of Medical Sciences and Research Hospital, \\ Tumkur, Karnataka, ${ }^{2,3}$ Prakash Institute of Medical Sciences (PIMS) and Research, Urun Islampur, Maharashtra, India
}

*Corresponding Author: R.H. Patil

Email: drrajhp@gmail.com

\begin{abstract}
Introduction: India has the highest number of tuberculosis in the world, accounting for nearly one fifth of the world's burden. Despite the national anti-tuberculosis program, tuberculosis remains the cause of death in India. The study, therefore, was designed to evaluate the RNTCP programme, which was revised by the evaluation and treatment of patients enrolled under the tuberculosis program in Umbraj, Maharashtra.

Materials and Methods: The present study was conducted at Tuberculosis Centre, Umbraj for the year 2014 which was record based study and information was collected by accessing the records maintained at the level of tuberculosis unit. All this information was collected for the year 2014 .

Result: In the present, the success rate for PTB was $87.7 \%$ and EPTB was $98.2 \%$. Among the pulmonary tuberculosis cases, cure rate was $54.4 \%$ while treatment completion rate was $33.3 \%$. Among the EPTB cases, treatment completion rate was $98.2 \%$ with death rate $1.8 \%$. The default rate of $2.0 \%$, transferred out rate of $1.0 \%$ and $2.6 \%$ failure rate were reported in year 2014 .

Conclusion: Tuberculosis suspect rate is consistently low at unit. Though microscopic activity and DOTS activity are appropriate there is deficiency in trained personnel and lacking in achievement of treatment outcome as per the guidelines.
\end{abstract}

Keywords: Revised national tuberculosis control programme, Tuberculosis unit, PTB, EPTB.

\section{Introduction}

Tuberculosis is an epidemic of infectious diseases caused by mycobacterium tuberculosis bacilli, which often affects the lungs that lead to tuberculosis. It can affect organs or any other system in the body, such as bones, lymph nodes leading to extra pulmonary tuberculosis. Age-related disorders are not only a public health problem, but also a social and economic problem for humankind. ${ }^{1}$

National Tuberculosis Control Program in India was started in 1962 with the aim to detect cases at the earliest and treatment. The program was implemented in the district through District Tuberculosis Centre (DTC) and the Primary Health Care Institutions with support from state level organizations for coordination and supervision of the program.

Approximately 2.2 million people have tuberculosis every year and more than 0.5 million die every year from the disease. ${ }^{2}$ The total number of people suffering from infection diseases in India is 14 million of which 3 to 3.5 million are positive for sputum. Every year about one million sputum positive cases have been added. ${ }^{3}$

With this in 1992, the India government, together with WHO and SIDA (Swedish International Development Agency) has revised the national program and found that treatment rate had ended only $30 \%$. Therefore, it has launched a revised National Tuberculosis Control Programme (RNTCP) with the goal of achieving at least $85 \%$ cure rate through DOTS and $70 \%$ of expected. ${ }^{3}$

India has the largest number of tuberculosis cases in the world, accounting for nearly one fifth of the global burden ${ }^{4}$. Tuberculosis is responsible for $5 \%$ of all death worldwide and $9.6 \%$ of adult deaths in the 15-59 years old economic productive age groups ${ }^{5}$. The case fatality rate of tuberculosis is high, approximately $50 \%$ of untreated cases die of the disease. One out of every three HIV/AIDS patients has tuberculosis. The key of this strategy is to cure tuberculosis through Directly Observed Treatment at a time and place convenient to the patient ${ }^{6}$. Case finding is passive detection by means of a patient friendly and clinically efficient services based primarily on smear microscopy. Still the transmission is higher and mortality and morbidity related to tuberculosis is higher may be due to co-infection with HIV/AIDS, Malnutrition and emergence of MDR-TB. Therefore, the current study is an attempt to evaluate the Revised National Tuberculosis Control Programme (RNTCP) through assessment and treatment of patients with tuberculosis registers in Tuberculosis unit of Umbraj, Maharashtra.

\section{Objectives}

To determine the treatment outcome of TB patients registered under Tuberculosis unit, Umbraj.

\section{Materials and Methods \\ Type of Study}

Record based observational cross-sectional study.

\section{Place of Study}

The present study was carried out at Tuberculosis Centre, Umbraj.

\section{Study Duration}

One year 


\section{Data Collection}

Information on the activity, diagnosis, treatment activities and treatment results were received. All this information was collected for 2014 by accessing the archives maintained at the TB unit. Investigator visited TB unit and collected information through the laboratory lists, registers, and treatment registers.

Ethical clearance was obtained prior to the commencement of the study. As per the guidelines of Revised National Tuberculosis Programme, Operational definitions were considered in the present study. ${ }^{7,8}$

\section{Statistical Analysis}

Data was entered in Excel and various performance indicators were calculated. Descriptive statistics such as mean, SD and percentage was used to present the data.

\section{Results}

Table 1: TB case detection activities

\begin{tabular}{|c|c|c|}
\hline Activities & No. of cases & Percentage \\
\hline Chest symptomatic & 1780 & 3.0 \\
\hline Ref for Sp exam & 1780 & 100.0 \\
\hline Sp +ve & 114 & 6.40 \\
\hline Repeat Sp Exam & 70 & 3.9 \\
\hline NSP & 114 & 6.40 \\
\hline
\end{tabular}

Table 2: Total TB case detection activities

\begin{tabular}{|c|c|c|}
\hline Activities & No. of cases & Percentage \\
\hline NSP & 114 & 44.2 \\
\hline NSN & 47 & 18.2 \\
\hline EPTB & 56 & 21.7 \\
\hline New TB & 217 & 84.1 \\
\hline Old sp +ve & 41 & 15.9 \\
\hline Only PTB & 202 & 78.3 \\
\hline
\end{tabular}

Table 3: Age wise distribution of PTB \& EPTB

\begin{tabular}{|c|c|c|}
\hline Age & PTB & EPTB \\
\hline $0-14$ & $6(9.8)$ & $5(23.8)$ \\
\hline $15-24$ & $39(11.2)$ & $11(14.3)$ \\
\hline $25-34$ & $52(10.1)$ & $10(7.6)$ \\
\hline $35-44$ & $43(7.2)$ & $7(6.4)$ \\
\hline $45-54$ & $35(9.9)$ & $7(6.1)$ \\
\hline $55-64$ & $12(5.4)$ & $3(4.6)$ \\
\hline$>65$ & $8(5.4)$ & $2(6.1)$ \\
\hline
\end{tabular}

Table 4: Treatment activities

\begin{tabular}{|c|c|}
\hline Activities & PTB \\
\hline On treatment & 195 \\
\hline Cat - I & 154 \\
\hline Cat - II & 41 \\
\hline Sp con Cat I & 95.5 \\
\hline Sp con Cat II & 64 \\
\hline
\end{tabular}

Table 5: Outcome of treatment of PTB \& EPTB

\begin{tabular}{|l|l|l|}
\hline Outcome & PTB $^{*}$ & EPTB $^{* *}$ \\
\hline
\end{tabular}

\begin{tabular}{|c|c|c|}
\hline On treatment & $195(77.7)$ & $56(22.3)$ \\
\hline Cure & $106(54.4)$ & - \\
\hline Treatment complete & $65(33.3)$ & $55(98.2)$ \\
\hline Death & $13(6.7)$ & $1(1.8)$ \\
\hline Failure & $5(2.6)$ & 0 \\
\hline Transferred out & $2(1.0)$ & 0 \\
\hline Default & $4(2.0)$ & 0 \\
\hline
\end{tabular}

*Success Rate: $87.7 \%, * *$ Success Rate: $98.2 \%$

\section{Discussion}

\section{Case Detection Activities}

For the year 2014, almost $18.2 \%$ of population were visited Out Patients Department (OPD) under at Umbraj Tuberculosis Units. Among chest pain symptoms were only $3.0 \%$ and of all $100 \%$ symptoms were targeted for sputum microscopy and $6.4 \%$ were found sputum smear positive for tuberculosis. Similar finding regarding sputum positivity was reported by N.M Kaore et al $(7.11 \%)$, ${ }^{9}$ while Ajaykumar et $\mathrm{al}^{10}(26.4 \%)$ showed a high sputum positivity compared to the present study.

In the current study, all new cases of tuberculosis, $78.3 \%$ were cases of Pulmonary tuberculosis and $25.8 \%$ were Extra-pulmonary tuberculosis cases respectively which was slightly higher than S Bisoi ${ }^{11}$ detected $67 \%$ new cases of pulmonary tuberculosis and $33 \%$ of cases of extrapulmonary tuberculosis in new detected tuberculosis cases, whereas Abhijit Mukherjee et al $^{12}$ reported $77.8 \%$ new pulmonary tuberculosis cases and $23.2 \%$ extra-pulmonary tuberculosis cases. Among all newly detected tuberculosis cases they found $50 \%$ were new sputum positive and $50 \%$ were sputum negative pulmonary tuberculosis cases. A.L DaCosta et $\mathrm{al}^{13}$ also found $67.47 \%$ of pulmonary tuberculosis cases and $32.52 \%$ were cases of extrapulmonary tuberculosis. In comparison with these studies the finding of present study seen higher. This difference may be due to study considered the reports after year 2012 and the comparison study were carried out before 2006 except A.L DaCosta et al who studied for a prolonged period of 9 years and also the present study considered all the Tuberculosis Units under District Tuberculosis Centre.

It was observed that in the present study most common affected age group was 15-34 years of age followed by 4554 years of age. This is suggestive of physical and economically active group was affected predominately, which may lead to increase in dependency, loss of income, poverty has the main earning people have got affected by the pulmonary tuberculosis. Similarly extra-pulmonary tuberculosis was also found higher among same age groups. Similar findings was reported by Bawri.S et al. ${ }^{14}$

\section{Treatment Activities}

Many studies have reported high proportion of pulmonary tuberculosis cases on Cat-I similar to the present study from $81 \%$ to $95.5 \%$. A Mishra et $\mathrm{al}^{15} ; \mathrm{S}$ L.Chandha et $\mathrm{al}^{16}$ and Abhijit $\mathrm{M}$ et al. ${ }^{12} \mathrm{~A}$ L.DaCosta et al ${ }^{13}$ have reported the patients on DOT, non DOT category though the non DOT category is phased out. This non DOT category was not 
found in present study area nor reported by the reference studies.

Almost similar sputum rate conversion by three months in case of pulmonary tuberculosis Cat-I was reported by Bawri S et al $;{ }^{14}$ and Gurpreet K et al. ${ }^{17}$ Simmi Tiwari et al ${ }^{18}$ reported the achieved below average $(84 \%)$ and $\mathrm{S}$ Bisoi, et $\mathrm{al}^{11}$ also foundpoor conversion rate $(74 \%)$ among new sputum positive cases.

The three month recovery of Sputum conversion rate of re-treatment cases was found to be lowest for $64 \%$ among Cat-II patients in contrast to sputum conversion rate among Cat-I $(95.5 \%)$. A Mishra et la ${ }^{15}$ reported $56 \%$ of sputum conversion rate and Abhijit $\mathrm{M}$ et al ${ }^{12}$, Md Shamim Akhtar et $\mathrm{al}^{19}$ have reported very low level of sputum conversion rate, in contrast to these studies Gurpreet $\mathrm{K}$ et al ${ }^{17}$ have reported highest sputum conversion rate among Cat-II patients.

\section{Treatment Outcome}

In the present study the cure rate among pulmonary tuberculosis cases were found more $54.4 \%$ as compared to study done by Mahesh $\mathrm{C}$ et $\mathrm{al}^{20}(43.3 \%)$, however, studies conducted by A. Mishra et $\mathrm{al}^{15}(85.04 \%)$ and S L Chadha et $\mathrm{al}^{16}(90 \%)$ had high cure rates among pulmonary tuberculosis cases. In the present study, treatment completion rate was found $33.3 \%$. The success rate was observed $87.7 \%$ for PTB and $98.2 \%$ got EPTB. Similar findings of average cure rate was given by A Mishra et al, ${ }^{15}$ $\mathrm{S}$ L.Chandha et $\mathrm{al}^{16}$, Puwar B et al ${ }^{21}$, Abhijit $\mathrm{M}$ et al, ${ }^{12} \mathrm{Md}$ Shamim Akhtar et al ${ }^{19}$ and Simmi Tiwari et al. ${ }^{18}$

In this study, the degree of success rate was established $87.7 \%$, similar findings were identified by R Prasad et al ${ }^{22}$ of $89.4 \%$. The level of default rate was achieved below $5 \%$ in the current study as per RNTCP guidelines ${ }^{7,8}$ and was low as compared to $32.5 \%$ in a study by Mahesh $\mathrm{C}$ et $\mathrm{al}^{20}$ and $3.79 \%$ by R Prasad et al. ${ }^{22}$ In the present study, high death rate $(6.7 \% \%)$ was observed as compared to SL Chadha et $\mathrm{al}^{16}(0.93 \%)$. Among pulmonary TB cases, the failure rate was found $2.6 \%$ in the current present which was slightly higher in study by SL Chadha et $\mathrm{al}^{16}(1.5 \%)$ and R Prasad et $\mathrm{al}^{22}(1.25 \%)$. Transferred out cases $(1.0 \%)$ were very less as compared to AL Da Costa et $\mathrm{al}^{13}(16.09 \%)$.

Among extrapulmonary TB patients, the treatment completion rate (98.2) in the present study was high in comparison to AL DaCosta et $\mathrm{al}^{13}(85.05 \%)$ and present study have achieved the targets of Revised National Tuberculosis Control Programme (RNTCP) guidelines ${ }^{7,8}$ $(\geq 90 \%)$. but the death rate in their study was less $(2.29 \%)$, whereas both transferred out $(16.09 \%)$ and default rates $(12.65 \%)$ were very high compared to the present study.

Among the treatment outcome extra-pulmonary tuberculosis cases, the death, default, failure and transferred out cases were within the limit of given targets by Revised National Tuberculosis Control Programme (RNTCP) guidelines. ${ }^{7,8}$

\section{Conclusion}

The overall success rate and treatment completion rate for pulmonary tuberculosis and extra-pulmonary tuberculosis is found coincidently with the national targets given by the Revised National Tuberculosis Control Programme. At tuberculosis unit, patients are satisfied with the services availing under Revised National Tuberculosis Control Programme. Though microscopic activity and DOTS activity are appropriate there is deficiency in trained personnel and lacking in achievement of treatment outcome as per the guidelines of Revised National Tuberculosis Control Programme.

\section{Conflict of Interest: None.}

\section{References}

1. Suryakantha AH. Community Medicine with recent advances, $3^{\text {rd }}$ edition. Jaypee; 2014.

2. A Guide for Practicing Physician-Revised National Tuberculosis Control Programme. Central TB Division. DGHS. Nirman Bhavan. New Delhi;45.

3. Khatri GR. The Revised National Tuberculosis Control Programme: a status report on the first 1, 00,000 patients. Indian J Tuberc 1999;46:157-66.

4. RNTCP Status Report; Annual Report 2006. Available from: http://www.tbcindia.org/documents.asp\#

5. WHO: World Health Reports 1999; Making a difference; Report of Director Gen. WHO, Geneva: WHO:1999

6. Introduction: Tuberculosis Control: Health Programme; Available from: http://gujhealth.gov.in/healthprogrammes/tb/index.htm

7. Supervision and Monitoring Strategy in Revised National Tuberculosis Control Program 2012

8. Technical and Operational Guidelines for Tuberculosis Control; Central TB Division 2005

9. Kaore NM, Date KP, Thombare VR. Increased sensitivity of sputum microscopy with sodium hypochlorite concentration technique: A practical experience at RNTCP center. Lung India: official organ of Indian Chest Society. 2011;28(1):17.

10. Verma AK, Mishra M, Singh A, Chaudhri S, Pandey S. Outcome of cases under Revised National Tuberculosis Control Programme at designated microscopy centre of a tertiary level hospital and medical college at Kanpur. UP J Clin Sci Res 2013;2:126-31.

11. Bisoi S, Sarkar A, Mallik S, Haldar A, Haldar D. A study on performance, response and outcome of treatment under RNTCP in a tuberculosis unit of Howrah district, West Bengal. Indian J Community Med 2007;32(4):245.

12. Mukherjee A, Saha I, Sarkar A, Chowdhury R. Gender differences in notification rates, clinical forms and treatment outcome of tuberculosis patients under the RNTCP. Lung India: official organ of Indian. Chest Soc 2012;29(2):120.

13. Da Costa AL, Keny SJ, Lawande D. Treatment outcome of pulmonary and extra pulmonary tuberculosis patients in TB and chest disease hospital DOT centre, Goa, India. Int J Curr Microbiol Appl Sci 2016;5:437-1.

14. Bawri S, Ali S, Phukan C, Tayal B, Baruwa P. A study of sputum conversion in new smear positive pulmonary tuberculosis cases at the monthly intervals of 1 st, 2nd \& 3rd month under directly observed treatment, short course (dots) regimen. Lung India: official organ of Indian. Chest Soc 2008;25(3):118.

15. Mishra A, Mishra S, Chouksey M, Gautam P, Verma P, Srivastava D. A study of effectiveness of DOTS on tuberculosis patients treated under RNTCP programme. NTI Bull 2007;43(3\&4):47-50.

16. Chadha SL, Bhagi RP. Treatment outcome in Tuberculosis patients placed under directly observed treatment short course (DOTS)-A cohort Study. Indian J Tuberc 2000;47(3):155-8. 
17. Kaur G, Goel NK, Kumar D, Janmeja AK, Swami HM, Kalia M. Treatment outcomes of patients placed on treatment under directly observed therapy short-course (dots). Lung India: official organ of Indian. Chest Soc 2008;25(2):75.

18. Tiwari S, Kumar A, Kapoor SK. Relationship between sputum smear grading and smear conversion rate and treatment outcome in the patients of pulmonary tuberculosis undergoing dots-a prospective cohort study. Indian J Tuberc 2012;59(3):135-40

19. Akhtar MS, Bhargava R, Ahmad Z, Pandey DK, Shah NN, Dar KA. To study the effectiveness of DOTS at JN Medical College Aligarh. Lung India 2007;24(4):128.

20. Mahesh C, Upadhyay C, Meena BP, Gaur KL. Treatment outcome of tuberculosis patient attended at DTC of SMS medical college, Jaipur (Raj.). Indian J Forensic Community Med 2014;1(1):19-22.
21. Puwar B, Patel V, Puwar T. A record based study on paediatric tuberculosis in Ahmedabad city, India. National J Comm Med 2012;3(1):153-6.

22. Prasad R, Verma SK, Shrivastava P, Kant S, Kushwaha RA, Kumar S. A follow up study on revised national tuberculosis control programme (RNTCP): Results from a single centre study. Lung India: official organ of Indian. Chest Soc 2008;25(4):142.

How to cite this article: Mandolikar RY, Patil RH, Madhekar NS, Mahabalaraju DK. A record based analysis of treatment outcome in Tuberculosis patients registered under Tuberculosis unit, Umbraj, District Satara of Western Maharashtra. Indian $J$ Forensic Community Med 2019;6(2):99-102. 